\title{
O ETANOL DA CANA DE AÇÚCAR: POSSIBILIDADES ENERGÉTICAS DA REGIÃO DE CEARÁ-MIRIM-RN
}

\author{
A. F. AQUINO, É. S. BIDÔ ${ }^{1}$, M. L. M. GALVÃO e V. N. OLIVEIRA \\ erica_bido@hotmail.com ${ }^{1}$
}

Artigo submetido em outubro/2011 e aceito em fevereiro2014

\section{RESUMO}

O uso indiscriminado de energias não renováveis, como o petróleo, vem reduzindo drasticamente as fontes de combustíveis fósseis e ocasionando graves prejuízos ambientais, como o agravamento do natural efeito estufa, o famoso aquecimento global, pelo lançamento excessivo de Dióxido de Carbono (CO2), dentre outros gases-estufa, na atmosfera. Tal fato vem chamando atenção para a importância de um desenvolvimento sustentável, realizando uma mudança intensa na matriz energética mundial, amplificando, então, a utilização de energias renováveis - eólica, solar, da biomassa, etc. como alternativa às não renováveis. Assim, esse trabalho apresenta o histórico e as vantagens de uma fonte de energia "limpa" que vem se destacando na matriz energética brasileira, com o foco na sua produção no Vale do Ceará-Mirim, no Rio Grande do Norte. Essa fonte é a cana-de-açúcar da qual é possível extrair o etanol que pode ser utilizado como opção à gasolina produzida a partir do petróleo. Seus co-produtos e subprodutos, como o açúcar, a garapa, a vinhaça e o bagaço também assumem grande importância econômica e sustentável. Dessa forma, os atuais métodos de cultivo e produção da cana-de-açúcar comprovam a possibilidade da integração entre o lado econômico e suas vantagens, o desenvolvimento sustentável e o aspecto social, portanto, é de extrema importância que o país invista nos potenciais energéticos presentes em seu território.

PALAVRAS-CHAVE: Energia, sustentabilidade, etanol, Ceará-Mirim.

\section{ETHANOL FROM SUGARCANE: POSSIBILITIES ENERGY OF CEARÁ-MIRIM-RN REGION}

\begin{abstract}
The indiscriminate use of non-renewable energy, like oil, is reducing the fossil fuels sources and causing serious environmental problems, such as the intensification of the natural greenhouse effect, the popular Global warming, caused by the excessive carbon dioxide emissions (CO2), and others greenhouse gases in the atmosphere. This fact draws attention to the importance of a sustainable development, promoting an intense change in the world energy matrix, increasing then the use of renewable energy - wind energy, sun energy, biomass etc. - like an alternative to non-renewable sources. This way, this work shows the history and the advantages of a "clean" energy source that has been detaching itself in the Brazilian energy matrix, focusing
\end{abstract}

its production in the Ceará-Mirim's Valley, Rio Grande do Norte state. This source is the sugarcane, from which the ethanol can be extracted. This fuel has big importance because it can be used as an option for the gasoline from oil. Its co-products and by-products, like the sugar, the garapa, the vinasse and the pulp also have a big economic and sustainable importance. In other words, the current methods of sugarcane growing and production of ethanol have shown that it's possible to associate economic advantages with sustainable development and social responsibility, so it's important to invest in the energetic potential that exists in our country.

KEYWORDS: Energy, sustainability, ethanol, Ceará-Mirim. 


\section{INTRODUÇÃO}

A relevância deste estudo está centrada na necessidade de modificações do atual modelo de desenvolvimento econômico, a fim de que seja possível o alcance de uma sociedade sustentável. Com isso, destaca-se a importância do estudo de fontes alternativas e limpas de energia, que visam a reduzir a grande demanda atual e a forte dependência dos combustíveis fósseis. Desta forma, espera-se uma maior dinamização da matriz energética atual.

Assim, considerando o grande potencial energético do Brasil na área de energias alternativas, desenvolvemos a pesquisa tendo como base o recorte espacial da região do Vale do Ceará-Mirim, a qual historicamente apresenta tradição na cultura canavieira, mas atualmente encontra-se em decadência, tendo como causas o atraso tecnológico e a permanência de infraestrutura inadequada, no que tange aos padrões de exigências da indústria energética atual, estando impossibilitada de produzir etanol.

O trabalho discute os conceitos Energias não-renováveis, Energias alternativas e Biomassa. Posteriormente fala sobre o Etanol, abordando seu processo de produção, e as vantagens e desvantagens de seu uso como combustível. Em seguida, é posto o contexto histórico brasileiro de cultivo de cana-de-açúcar e produção de etanol, dando destaque, em seguida, ao recorte espacial Vale do Ceará-Mirim.

A pesquisa se desenvolve com base na construção de um referencial bibliográfico, alicerçado em revistas científicas, artigos produzidos pelo BANCO NACIONAL DE DESENVOLVIMENTO (BNDES), O DEPARTAMENTO DA CANA-DE-AÇÚCAR E AGROENERGIA, MONTENEGRO, M. E., entre outros. A metodologia prevê ainda visita in loco para visualização do processo produção do etanol.

Esta pesquisa é financiada pelo Programa de Formação de Recursos Humanos da Petrobras (PFRH), em parceria com o Instituto Federal de Educação, Ciência e Tecnologia do Rio Grande do Norte (IFRN), e tem como objetivo destacar o uso do etanol, proveniente da cana-deaçúcar, como uma fonte de energia alternativa, considerando também os impactos sociais e ambientais advindos dessa atividade.

\section{ENERGIAS}

\subsection{ENERGIA}

Segundo José Goldemberg (2000, p.91) "a energia é um ingrediente essencial para o desenvolvimento." É ela quem proporciona todo o ciclo de atividades fundamentais aos seres humanos e de desenvolvimento econômico. Em sentido literal pode-se dizer que a energia move o mundo.

A partir da Revolução Industrial o consumo energético começou a aumentar em grandes proporções, fazendo com que hoje, esse aumento constante torne-se uma preocupação quanto ao futuro do nosso planeta, uma vez que a maioria das fontes energéticas utilizadas ainda são fontes não renováveis. 
Energias não renováveis são aquelas provenientes dos recursos considerados não renováveis, que possuem essa denominação devido ao fato de serem encontrados naturalmente na natureza de forma limitada. Exemplos desses recursos são os chamados combustíveis fósseis (petróleo, carvão, gás natural).

Atualmente, grande parte da energia mundial é proveniente de recursos não renováveis, o consumo e a demanda aumentam cada vez mais, visto que tais recursos impulsionam as inovações tecnológicas. Dessa forma, com o aumento da demanda, e por apresentarem um longo período de formação, os recursos não renováveis podem se esgotar, o que faz com que pensemos sobre novas matrizes energéticas.

Outro grande problema que circunda a utilização desses tipos de combustíveis e fontes energéticas são os problemas ambientais e de saúde provenientes deles. A queima desses combustíveis libera os gases precursores do aceleramento do natural efeito estufa, e, consequentemente, o surgimento do fenômeno do aquecimento global. Segundo ANDRADE; CARVALHO; SOUZA (2009, p.128):

O grande nível de utilização dos combustíveis fósseis, na geração de energia para as indústrias, casas, aquecimento domiciliar e como propulsão das frotas de coletivos e dos carros particulares, a intervenção danosa do homem na natureza, pós-período da revolução industrial é o que tem causado tudo isso.

Devido ao alto grau de poluição e aos prejuízos ambientais que são causados por essas fontes energéticas, sua energia é dita como energia "suja".

Diante de tal situação, de escassez e prejuízos ambientais, torna-se urgente a mudança na matriz energética mundial, de fontes não renováveis para as chamadas energias alternativas. 0 potencial brasileiro para exploração de fontes alternativas de energia é gigantesco: grandes quantidades de terras férteis disponíveis para a produção de biomassa; ventos e clima propícios para a energia eólica; capacidade de captação dos raios solares para a transformação em eletricidade.

No entanto, apesar dos seus fatores favoráveis às energias alternativas - espaço disponível e clima apropriado - faltam investimentos no Brasil. A maioria desse potencial ainda não é aproveitada, pois faltam programas de incentivo a utilização dessas energias e pesquisas de tecnologias e formas de aprimoramento que possam torná-las cada vez mais viáveis.

\subsection{ENERGIAS ALTERNATIVAS}

Energias Alternativas são energias renováveis que têm o caráter cíclico e baixo impacto negativo sobre o meio ambiente. São assim chamadas, pois o ser humano encontrou nelas a alternativa para mitigar as condições ambientais do Planeta.

Preocupado com os acidentes ambientais, a saber, o vazamento de petróleo no Golfo do México (20 de abril de 2010 e o acidente nuclear no Japão (11 de março de 2011); e com as mudanças climáticas, o homem está cada vez mais interessado em promover o Desenvolvimento Sustentável, por meio da ampliação do uso de energias alternativas, como a eólica, a solar, a geotérmica, a hidráulica, a das marés, do hidrogênio e a biomassa, que estão presentes em todo o mundo, o que possibilita a sua utilização de maneira descentralizada. 
Esse modo "limpo" de gerar energia é capaz de proporcionar o aumento da oferta de energia; a garantia da sustentabilidade e da renovação dos recursos; e a redução das emissões atmosféricas de poluentes. Além disso, em alguns casos, é economicamente viável e abundante.

Porém, os custos em infraestrutura para a captação de energias renováveis, geração, condicionamento, armazenamento e distribuição dela, às vezes, se tornam muito elevados, e o retorno sempre é a longo prazo, o que faz com que governos e investidores temam em investir nessas energias; por isso, o processo de utilização da energia "limpa" como opção às energias "sujas" é muito lento.

\subsection{BIOMASSA}

Biomassa é todo recurso renovável originado a partir de matéria orgânica (vegetal ou animal) que pode ser utilizada na produção de energia. Através da fotossíntese, a energia solar é convertida em energia química, e, posteriormente, pode ser transformada em eletricidade, combustível ou calor.

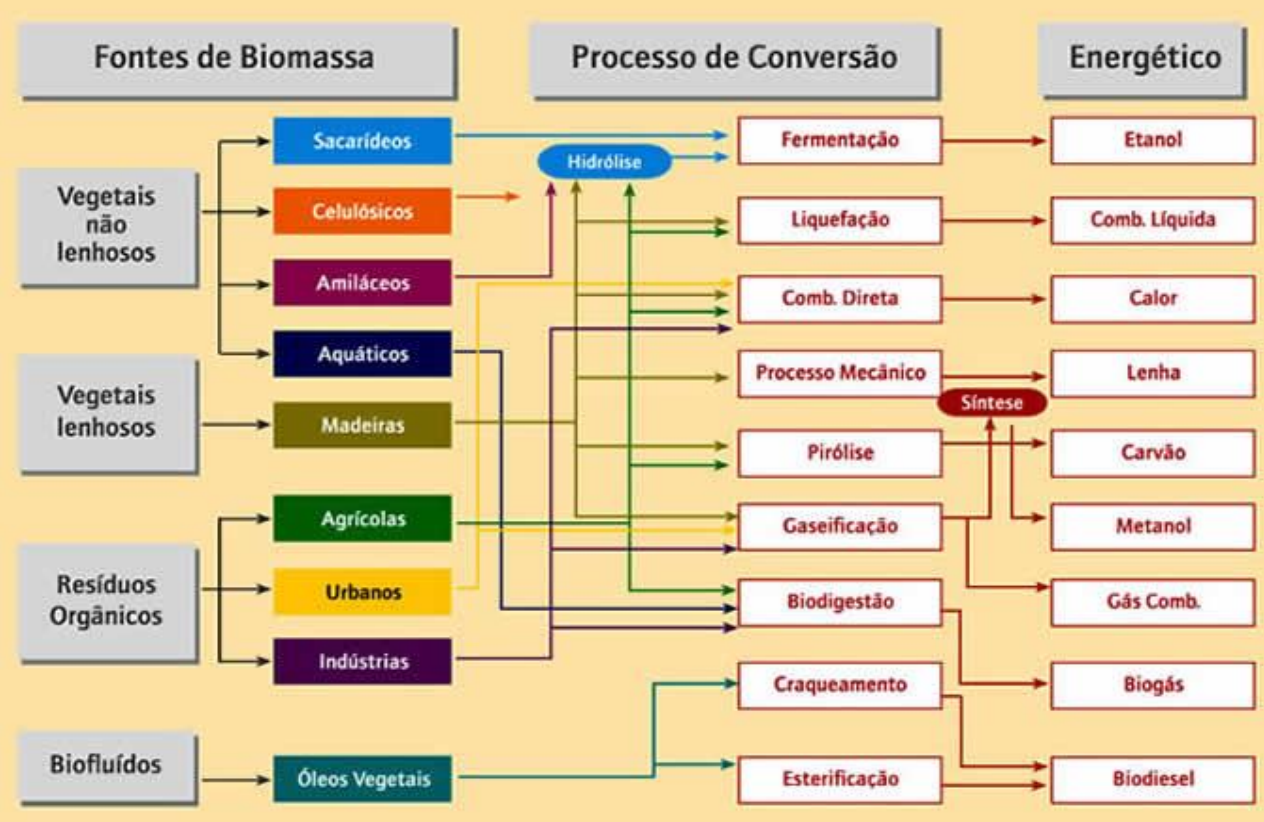

Figura 1 - Diagrama esquemático dos processos de conversão energética da biomassa.

Fonte: AGÊNCIA NACIONAL DE ENERGIA ELÉTRICA. Biomassa. Disponível em:

<http://www.aneel.gov.br/aplicacoes/atlas/pdf/05-Biomassa\%282\%29.pdf>.

No Brasil, a biomassa de origem vegetal é a mais utilizada, com destaque para as gramíneas, como a cana-de-açúcar. Torna-se evidente a interdependência em relação aos fatores naturais, tais como insolação, temperatura, disponibilidade hídrica e fertilidade dos solos, tendo o Brasil grande potencial para o setor, como afirma AGÊNCIA NACIONAL DE ENERGIA ELÉTRICA (2011, p. 78):

No Brasil, a imensa superfície do território nacional, quase toda localizada em regiões tropicais e chuvosas, oferece excelentes condições para a produção e o uso energético da biomassa em larga escala. Além da produção de álcool, queima em fornos, caldeiras e outros usos não-comerciais, a biomassa apresenta grande potencial no setor de geração de energia elétrica. 
O uso da biomassa tem sido defendido, tendo em vista o risco de exaustão de fontes nãorenováveis e pressões ambientalistas. Assim, tem-se feito pesquisas para desenvolver e aperfeiçoar as tecnologias de conversão, buscando maior eficiência do processo e redução dos impactos socioambientais.

\subsection{O ETANOL}

Etanol (álcool etílico combustível), produto renovável e limpo, corresponde a um a um tipo de álcool constituído por dois átomos de carbono, cinco átomos de hidrogênio e um grupo hidroxila. O etanol é uma substância pura, composta por um único tipo de molécula: $\mathrm{C}_{2} \mathrm{H}_{5} \mathrm{OH}$. Originado da biomassa, ele pode ser obtido a partir de diferentes matérias primas, tais como milho, beterraba, trigo e cana-de-açúcar.

É necessário, porém, uma diferenciação entre o etanol hidratado e o etanol anidro. A diferença consiste no teor de água apresentado em cada tipo. Enquanto o etanol hidratado apresenta cerca de $5 \%$ de água em seu volume, o etanol anidro possui em torno de $0,5 \%$. 0 abastecimento dos automóveis flex é feito pelo etanol hidratado, já o anidro é geralmente misturado na gasolina numa proporção de $20 \%$ a $25 \%$, definida pelo governo federal de acordo com a produção e disponibilidade do produto.

\subsubsection{CANA-DE-AÇÚCAR E PRODUÇÃO DE ETANOL}

A cana-de-açúcar é uma planta com ciclo fotossintético do tipo C4, do gênero Saccharum e da família Graminae, composta por espécies perenes de grama alta. Sua produção representa uma das mais importantes culturas comerciais do mundo, ocupando mais de 20 milhões de hectares, dos quais 7 milhões encontram-se em território brasileiro. Assim o Brasil se destaca como o maior produtor mundial de cana-de-açúcar, responsável por cerca de $42 \%$ da produção total e apresentando uma produtividade média em torno de 70t/ha (BNDES, 2008, p. 68 e 70).

Geralmente as atividades agrícolas se iniciam cerca de dois a três anos antes da produção efetiva para fins industriais, a fim de permitir uma produção de matéria-prima estável dentro de três a quatro anos.

O clima ideal para o seu cultivo é aquele que tem duas estações bem definidas: uma quente e úmida, para tornar possível seu surgimento e desenvolvimento vegetativo; e uma estação fria e seca, que promove a maturação e consequente acúmulo de sacarose nos caules.

A colheita ocorre normalmente após os períodos de chuvas, procurando alcançar o melhor ponto de maturação e o acúmulo máximo de sacarose na planta, e também para que possam ser realizadas as operações de corte e transporte.

A rota tecnológica utilizada para a produção de etanol varia de acordo com a matériaprima utilizada, como pode ser observado no esquema abaixo. Sua produção a partir da cana-deaçúcar inicia-se com a extração ou difusão, seguindo os passos de fermentação e destilação. 


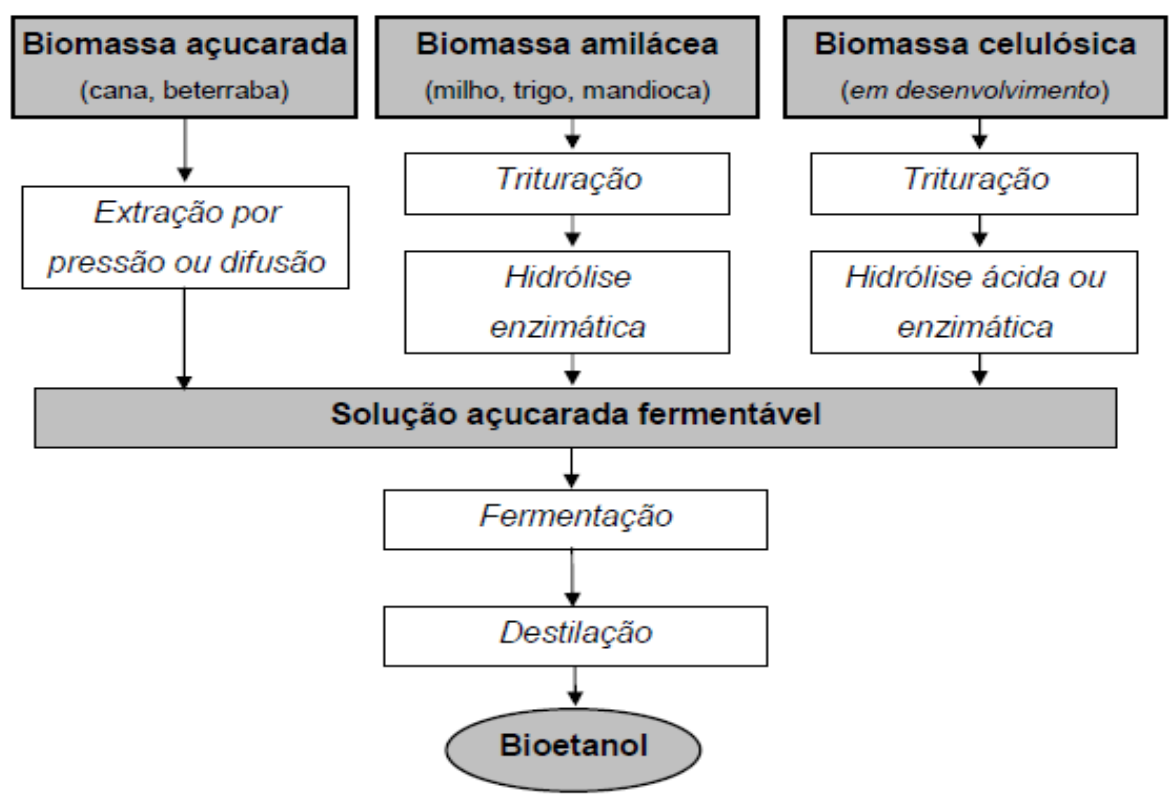

Figura 2 - Rotas tecnológicas para a produção de etanol.

Fonte: BNDES. et al. Bioetanol de cana-de-açúcar: energia para o desenvolvimento sustentável. Disponível em: <http://www.bioetanoldecana.org/pt/download/resumo_executivo.pdf >.

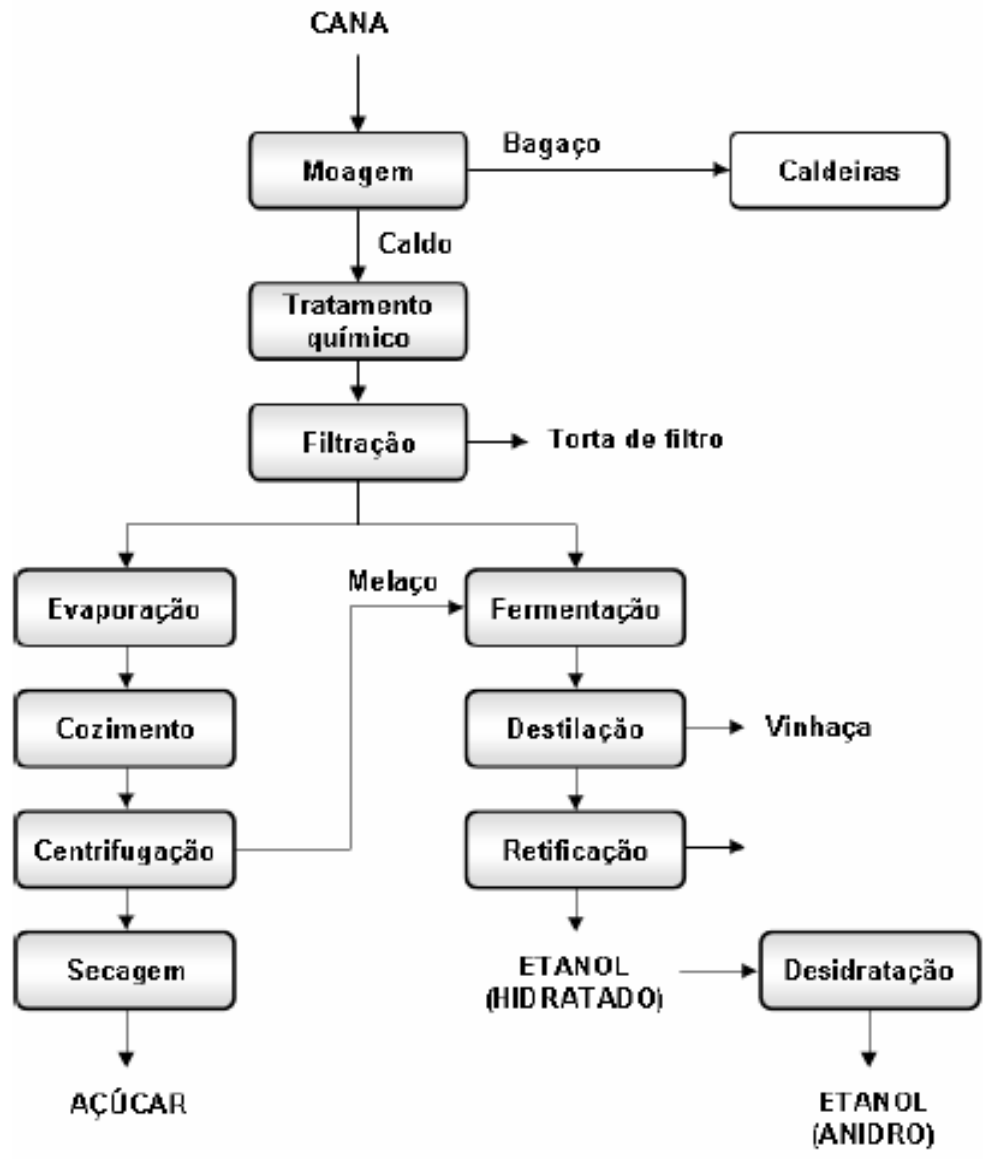

Figura 3 - Esquema da produção de açúcar e etanol.

Fonte: BNDES. et al. Bioetanol de cana-de-açúcar: energia para o desenvolvimento sustentável. Disponível em: <http://www.bioetanoldecana.org/pt/download/resumo_executivo.pdf>. 
No contexto brasileiro, a produção de bioetanol da cana-de-açúcar é realizada geralmente em unidades agroindustriais que também produzem açúcar. Assim, há uma forte interação entre os dois processos produtivos, pois utilizam em comum os equipamentos de extração (moendas ou difusores) e apresentam diferenças apenas no fim de cada processo, como mostra a Figura 03.

A cana que chega à unidade agroindustrial é processada o mais rapidamente possível, para evitar sua contaminação ou deterioração, por isso é de grande importância o sincronismo nas etapas de corte, transporte e moagem.

De modo simplificado, as principais etapas para a produção do etanol são as seguintes:

\section{- Lavagem e Moagem}

Inicialmente a cana é lavada para que a terra ainda proveniente da lavoura possa ser retirada. Depois de abertas e desfibradas, as células de cana são enviadas à moenda, onde é extraído o caldo.

\section{- Evaporação e Preparo do mosto}

Durante a evaporação, o caldo é aquecido em torno de $115^{\circ} \mathrm{C}$. Com a retirada de água, o caldo fica mais concentrado. $\mathrm{O}$ caldo quente é resfriado a $30^{\circ} \mathrm{C}$ em trocadores de calor, formando o mosto ou melaço, que consiste numa solução fermentescível de $40 \%$, aproximadamente, de sacarose.

\section{- Fermentação}

Etapa que consiste no processo de transformação anaeróbia dos açúcares em etanol (álcool etílico) e gás carbônico, a partir de enzimas fornecidas por microrganismos denominados leveduras (as linhagens geralmente utilizadas são de Saccharomyces), durando em torno de 8 a 12 horas. Para um melhor desempenho, as dornas devem ser fechadas para recuperarem o álcool arrastado pelo gás carbônico. Além disso, os trocadores de calor mantêm as temperaturas ideais para as leveduras (em torno de $28^{\circ} \mathrm{C}$ a $30^{\circ} \mathrm{C}$ ). É importante que a levedura possua um crescimento vigoroso e uma elevada tolerância ao etanol, apresentando assim um elevado rendimento final. O mosto fermentado é denominado Vinho.

\section{- Centrifugação do vinho}

Ocorre a separação entre o vinho e o fermento, possibilitando o tratamento prévio das leveduras, para que possam ser utilizadas em novos ciclos fermentativos.

\section{- Destilação}

O vinho delevurado, contendo aproximadamente $9,5 \%$ ou $10 \%$ de álcool, irá para os aparelhos de destilação fracionada, onde o álcool é removido dos sólidos e da maior parte da água. A solução final apresenta um teor alcoólico de $96^{\circ} \mathrm{GL}$ : $96 \%$ de álcool etílico e $4 \%$ de água.

\section{- Desidratação}

Nesta etapa, é removido água da solução destilada. Geralmente é realizada através da adição de ciclohexano, que juntamente com a água, forma uma mistura azeotrópica ternária que entra em ebulição antes do bioetanol. Ao fim do processo, essa mistura é enviada à coluna de recuperação de ciclohexano, para que ele seja retirado e possa ser utilizado novamente, já o combustível resultante apresenta cerca de $0,4 \%$ de água (etanol anidro). 
A desidratação também pode ser realizada por meio de peneiras moleculares ou pela destilação extrativa utilizando monoetilenoglicol, que embora consumam menos energia, apresentam custos mais elevados. Já que o etanol anidro proveniente do processo que utiliza tais peneiras é livre de contaminantes, estimula diversos produtores brasileiros e de outros países a optarem pelo seu uso, uma vez que as exigências do mercado tornam-se cada vez maiores (BNDES, 2008, p. 76).

\subsubsection{VANTAGENS DO ETANOL}

O etanol é considerado, praticamente, a melhor alternativa para os derivados do petróleo e, pode ser oriundo de duas fontes principais: do milho e da cana. Quando proveniente da cana, no caso do Brasil, apresenta expressiva vantagem em relação ao etanol do milho, no caso dos norte americanos, uma vez que para cada hectare cultivado de cana são produzidos, em média, 6800 litros de álcool, enquanto que a mesma área cultivada de milho fornece apenas 3200 litros, ou seja, a cana-de-açúcar tem uma rentabilidade muito maior do que o milho.

Sabe-se que o etanol está cada vez mais sendo utilizado como combustível, devido a sua capacidade de competitividade com os derivados do petróleo, como a baixa toxidez e a elevada biodegradabilidade, e o alto teor de oxigênio, que constitui cerca de $35 \%$ em massa do etanol. Generalizando, as características do etanol possibilitam uma combustão mais limpa e melhor desempenho dos motores, o que contribui para redução das emissões poluentes.

O processo de produção do etanol em si consome significativa quantidade de energia térmica, mecânica e elétrica, porém, no caso da agroindústria com base na cana, essas demandas cada vez mais estão sendo supridas a partir de um sistema combinado de produção de calor e potência (sistema de cogeração) instalado na própria usina. Esse sistema utiliza apenas bagaço como fonte de bioeletricidade, e ainda tem a possibilidade de gerar excedentes para a rede pública. Acredita-se que 0,55 toneladas de carbono deixam de ser emitidas por tonelada de bagaço processado para gerar eletricidade. Além do mais, a produção de energia elétrica com base no bagaço é elegível para a obtenção de créditos de carbono, conforme o Protocolo de Quioto. Segundo BNDES et al (2008, p.10):

No início de 2008, a capacidade instalada nas usinas de açúcar e etanol no Brasil era de 3,1 GW e há perspectivas de que a geração de energia elétrica para a rede pública com base no bagaço possa alcançar $15 \mathrm{GW}$ até 2015 , ou $15 \%$ da atual potência instalada nas centrais elétricas brasileiras.

Esse processo de produção do etanol também exige uma grande quantidade de água, de terra e de agroquímicos, entre outros. Mas já são priorizados cultivos que minimizam esses requerimentos e que prezam pela viabilidade econômica. Por meio dele são gerados ainda coprodutos e subprodutos, de valor alimentício, industrial ou energético, como o açúcar, o melaço, a aguardente, o bagaço, a levedura, a torta de filtro e a vinhaça. Essa última é utilizada nos sistemas de fertirrigação, permitindo ampliar a produtividade agrícola e a reduzir o emprego de fertilizantes, pois consiste num composto rico em nutrientes necessários ao crescimento vegetal, como o potássio $\left(\mathrm{K}_{2} \mathrm{O}\right)$, e possibilitando atenuar os impactos sobre o meio ambiente, visto que esse resíduo do processamento da cana era lançado diretamente nos rios, afetando o ecossistema e também reduziu os riscos de salinização e contaminação dos lençóis freáticos, ao ser usado como fertilizante orgânico em substituição aos químicos. Essas inovações conferem 
certa flexibilidade na produção de bioenergia, já que agrega fontes de valor econômico a disponibilidade de biocombustíveis.

Conforme a SECRETARIA DE POLÍTICA AGRÍCOLA DO MINISTÉRIO DA AGRICULTURA, PECUÁRIA E ABASTECIMENTO (2006, p. 57):

[...] atualmente, a vinhaça é aplicada sobre o solo de forma controlada, como um fertilizante orgânico, deixando de ser um produto indesejável. Normalmente, aplica-se a vinhaça nas próprias áreas colhidas, localizadas nas proximidades das usinas, por meio de sistemas de irrigação por bombeamento ou canal.

Levando em consideração que a cana é um cultivo semiperene, essa característica associada a técnicas agrícolas adequadas favorece a redução da erosão e a proteção da fertilidade do solo. Além do mais, ela pode ser associada ao cultivo de lavouras alternativas, como as de milho, de soja, entre outras.

O MINISTÉRIO DAS RELAÇÕES EXTERIORES apud OTTONI (2000, p. 178) expõe que:

O cultivo da cana usa baixo nível de defensivos; tem o maior programa de controle biológico de pragas do país; tem o menor índice de erosão do solo; recicla todos os resíduos; não compromete a qualidade dos recursos hídricos e representa a maior área de produção orgânica do país.

Com relação aos subprodutos, há um vasto campo de aplicações para a cana-de-açúcar e para o etanol, como a produção de polímeros diversos, seja no contexto da indústria petroquímica convencional, que vem incluindo o etanol entre os insumos, seja no âmbito da etanolquímica, a qual abrange processos mais específicos e avançados, como, por exemplo, a fabricação de plásticos biodegradáveis, em desenvolvimento no Brasil.

É importante destacar ainda o balanço energético da biomassa utilizada para a produção do etanol, isto é, a relação entre a energia produzida e a demanda de energia direta ou indireta para produzir tal energia. A partir disso, é possível estimar os níveis de emissão de gases do efeito estufa (GEE), para cada matéria-prima utilizada. Considerando a produção do etanol, na Tabela 1, apresentam-se os valores para os balanços energéticos e o nível de emissões de GEE evitadas, para cada biomassa, o que torna possível perceber que a redução das emissões dos gases do efeito estufa é um dos efeitos positivos mais relevantes do etanol proveniente da canade-açúcar.

Tabela 1: Comparação das matérias-primas para a produção do etanol

\begin{tabular}{|l|c|c|}
\hline Matéria-prima & Relação de energia & Emissões evitadas \\
\hline Cana & 9,3 & $89 \%$ \\
\hline Milho & $0,6-2,0$ & $-30 \%$ a $38 \%$ \\
\hline Trigo & $0,97-1,11$ & $19 \%$ a $47 \%$ \\
\hline Beterraba & $1,2-1,8$ & $35 \%$ a $56 \%$ \\
\hline Mandioca & $1,6-1,7$ & $63 \%$ \\
\hline Resíduos lignocelulósicos* & $8,3-8,4$ & $66 \%$ a $73 \%$ \\
\hline
\end{tabular}

*Estimativa teórica, processo em desenvolvimento.

Fonte: BNDES. et al. Bioetanol de cana-de-açúcar: energia para o desenvolvimento sustentável. Disponível em: <http://www.bioetanoldecana.org/pt/download/resumo executivo.pdf >. 
Segundo a Comunicação Brasileira para a Convenção-Quadro das Nações Unidas para Mudança do Clima (1994, apud BNDES; CGEE; FAO; CEPAL, 2008, p. 9) a utilização da energia da cana reduziu em $13 \%$ as emissões de carbono de todo o setor energético. Nas condições atuais, para cada 100 milhões de toneladas de cana-de-açúcar destinadas a fins energéticos, poderia ser evitada a emissão de 12,6 milhões de toneladas de $\mathrm{CO}_{2}$.

Outra vantagem do etanol está representada na figura 4, abaixo, que é a sua competitividade em relação aos combustíveis fósseis no que tange os preços finais para o consumidor. Como podem ser observados, os valores de mercado para o bioetanol são significativamente inferiores comparados com os valores dos combustíveis fósseis. Pesquisadores ainda afirmam que se derem continuidade ao processo de incremento da produtividade agrícola e industrial, é razoável esperar que os custos de produção do etanol de cana-de-açúcar permaneçam estáveis ou sejam reduzidos, enquanto, do lado dos combustíveis fósseis, os cenários esperados são de manutenção de preços elevados. Portanto, do ponto de vista econômico, a produção de etanol a partir da cana-de-açúcar mostra-se sustentável, com preços e custos efetivamente viáveis, sem necessidade de subsídios para competir com os combustíveis convencionais.

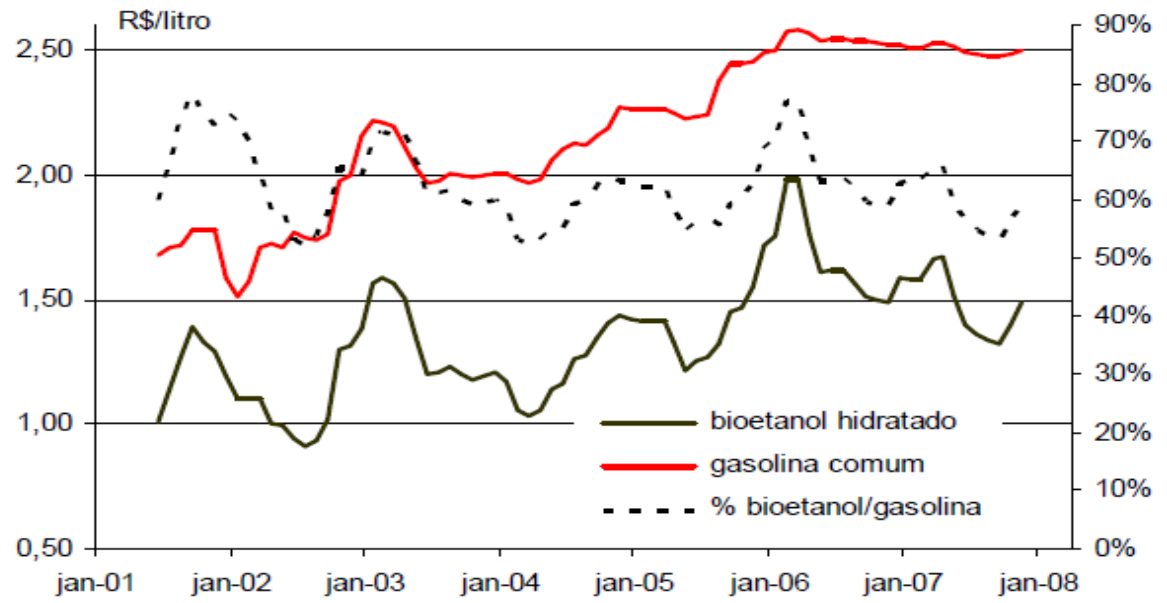

Figura 4 - Evolução dos preços médios ao consumidor do bioetanol hidratado e da gasolina comum e da relação entre esses preços no Brasil.

Fonte: BNDES. et al. Bioetanol de cana-de-açúcar: energia para o desenvolvimento sustentável. Disponível em: <http://www.bioetanoldecana.org/pt/download/resumo executivo.pdf >.

A geração de empregos com o correspondente acréscimo dos requisitos de capacitação e da remuneração média podem ser citados em casos como o do Brasil, por exemplo, como outros pontos favoráveis da produção do etanol. A maioria dos empregos se refere a trabalhadores rurais contratados para a execução de atividades de corte e manejo da cana, em período de colheita. Essa situação sinaliza melhorias importantes em diversos indicadores socioeconômicos para os trabalhadores na lavoura da cana-de-açúcar, como ganhos reais de salários, aumento dos benefícios recebidos pelos trabalhadores, redução do trabalho infantil e elevação da escolaridade.

Apesar dessas melhorias, as atividades manuais da produção do etanol são geralmente pesadas e compete ao Estado a frequente fiscalização do cumprimento da legislação trabalhista, 
essencial para conter as distorções existentes e promover o avanço das relações de trabalho nesse setor.

Por fim, reitera-se que o etanol proveniente da cana-de-açúcar se distingue das fontes fósseis de energia devido ao seu reduzido impacto ambiental, especialmente quando seu processo é acompanhado de medidas de fiscalização, controle e planejamento.

\subsubsection{DESVANTAGENS DO ETANOL}

Ao falar das desvantagens do etanol uma das primeiras questões que é abordada referese aos problemas ambientais advindos do processo de queima da cana-de-açúcar, uma vez que esse processo de combustão gera uma intensa carga de emissões de poluentes para a atmosfera, dentre eles estão os óxidos de nitrogênio (NOx) e enxofre (SOx) e o monóxido de carbono (CO), esses gases causam efeitos diretos para a saúde, principalmente no trato respiratório das pessoas que residem próximo a área da queima e dos trabalhadores presentes nos canaviais. Entretanto esse problema começa a ser solucionado, pois esse processo é utilizado para facilitar a colheita manual da cana-de-açúcar. Com a complementação do trabalho manual por máquinas, sendo dispensado gradativamente a prática de queima - essencial para a colheita manual. Além do mais, visando à preservação do meio ambiente, alguns estados brasileiros já começaram a instituir leis que proíbem a queima da cana, como o Estado de São Paulo, por meio da Lei no 11.241, de 19 de setembro de 2002.

É evidente que assim como qualquer atividade agrícola, o cultivo da cana-de-açúcar também traz malefícios para a área da plantação, porém sendo utilizadas práticas adequadas de manejo e havendo respeito às características específicas da área plantada, a atividade torna-se sustentável. Outro aspecto que deve ser analisado em relação à área da plantação é a possibilidade de compactação do solo, devido ao peso da maquinaria que se movimenta sobre ele, entretanto existem técnicas agrônomas que podem facilmente ser utilizadas para evitar ou minimizar esse efeito.

No Brasil a destinação de terras para produção de cana-de-açúcar para etanol é questionada, pelos que temem a falta de terras para produção de alimentos, uma vez refletido o caso particular dos Estados Unidos, os quais passaram a produzir etanol a partir do milho e isso Ihes trouxeram redução da produção para a alimentação do país, tanto pela ausência de áreas, quanto pela falta do milho na alimentação diária das pessoas. Contudo, vale ressaltar que no Brasil a questão se diferencia mediante a comprovação de que a utilização da cana-de-açúcar para a produção de etanol não acarreta grandes diminuições na produção de açúcar, principal produto advindo da cana utilizado na alimentação. Como podemos ver na tabela 2 a quantidade de cana de açúcar destinada para as duas produções (álcool e açúcar) é equilibrada, sendo para cada uma destinada praticamente metade da quantidade total de cana-de-açúcar produzida.

Segundo a Secretaria de Política Agrícola do Ministério da Agricultura, Pecuária, e Abastecimento (2006, p. 56) "A Embrapa estima haver cerca de 90 milhões de hectares disponíveis para expansão da agricultura no Brasil, [...] A atual área plantada com cana-de-açúcar é pouco superior a 6 milhões de hectares (safra 2005-2006), ou seja, menos de 1\% do território nacional.

Em se tratando do processo industrial da cana-de-açúcar, é reconhecível que o seu processamento gera vários resíduos, que caso não recebam o destino adequado, causarão 
impactos no meio ambiente. Exemplos desses resíduos são o bagaço e o vinhoto. Porém, como já foi mencionado anteriormente, por meio do aumento das condições tecnológicas para as pesquisas e da preocupação ambiental, já foram encontradas atualmente formas de aproveitamento desses resíduos. Como já foi dito, o vinhoto pode ser aproveitado para a produção de biogás, utilizado como fertilizante agrícola ou ainda obter outros fins na indústria química. E o bagaço da cana pode ser utilizado na produção de energia - térmica, mecânica e elétrica - que pode ser aproveitada no próprio processo de produção do etanol e do açúcar.

Tabela 2: Panorama do setor sucroalcooleiro no Brasil

\begin{tabular}{|c|c|c|c|c|c|}
\hline \multicolumn{2}{|c|}{ PRODUÇÃo } & & & & VARIAÇÃO ENTRES \\
SAFRAS
\end{tabular}

Fonte: DEPARTAMENTO DA CANA-DE-AÇÚCAR E AGROENERGIA. Açúcar e álcool no Brasil. Disponível em: <http://www.agencia.cnptia.embrapa.br/Repositorio/alcool acucar no brasil mapa 000fl6j9ex702wyiv80ispcrrqur 3jat.pdf>.

Quanto ao uso de etanol como combustível é fato que ele gera emissões de aldeídos, que são compostos tóxicos, ainda maiores que a gasolina e o diesel. No entanto, o aldeído gerado pelo etanol, é acetaldeído, que é menos tóxico do que os aldeídos gerados por esses outros combustíveis. Além do mais, essas emissões podem ser facilmente evitadas por meio de catalisadores presentes nos veículos, que no Brasil já são obrigatórios desde 1992.

Portanto, é possível perceber que o etanol pode substituir os combustíveis fósseis utilizados atualmente, uma vez que aquele apresenta consideráveis vantagens e suas desvantagens são mínimas em comparação, por exemplo, à gasolina e ao diesel.

\section{CONTEXTO HISTÓRICO}

\subsection{CANA-DE-AÇÚCAR E O PERÍODO COLONIAL}

Com a chegada dos portugueses no Brasil em 1500, teve início o Período Colonial brasileiro que se estendeu até 1822. Durante a maior parte deste período, a intervenção portuguesa assumia caráter claramente extrativo, alcançando de formas e intensidades diferentes o território do país.

Logo nos primeiros anos da colonização, a extração do pau-brasil se destacou como a principal atividade econômica e era obtido, basicamente, através de escambo com a população nativa. 
A partir do momento que o Brasil passou a ser colonizado efetivamente por Portugal, foi criado o sistema de capitanias hereditárias, que marcou início de uma exploração mais sistemática da colônia com o desenvolvimento de diferentes atividades econômicas promovidas pelos colonos.

A região Nordeste, mais precisamente a faixa litorânea, foi a que mais sofreu com as decisões sobre a exploração econômica da coroa portuguesa, uma vez que era a mais próxima da Europa e possuía características climáticas favoráveis. Já a região Sudeste não sofria com tanta intervenção, inicialmente, e as atividades desenvolvidas aí eram mais diversificadas e iam de acordo com os interesses dos colonos.

Entre as atividades desenvolvidas na fase colonial, como cana-de-açúcar, fumo, mineração, café, algodão, pecuária, entre outras, duas se destacaram na formação econômica brasileira e, por isso, são denominados ciclos econômicos: o da cana-de-açúcar e o da mineração. Nessa discussão será considerado o ciclo da cana-de-açúcar.

O ciclo do açúcar vai do início da colonização até 1760. Até o século XVII, o Brasil era o maior produtor de açúcar do mundo, tendo os Estados da Bahia e de Pernambuco como os principais centros açucareiros da época. Conforme Fausto (2006), de 1570 a 1670, o Brasil vivenciou o "século do açúcar", um período de intensa produção e lucro do negócio açucareiro.

Devido aos rendimentos dessa atividade, os portugueses passaram a buscar mais terras para expandir a cultura canavieira e a criação de gado para abastecer os engenhos, chegando, assim, à capitania do Rio Grande do Norte.

Os primeiros engenhos estabelecidos na citada capitania se localizavam na sua porção oriental, sendo eles o engenho de Cunhaú e o engenho Ferreiro Torto, os quais foram destruídos pelos holandeses em 1631. Diante disso, os portugueses expulsaram os holandeses e dividiram a capitania em sesmarias, as quais foram entregues, cada uma, a homens escolhidos pela coroa portuguesa. João Fernandes Vieira foi quem recebeu a sesmaria que mais tarde veio a ser o município de Ceará-Mirim. Porém, ele ignorou a doação e só posteriormente seus filhos tomariam posse das terras.

Assim, só mais tarde, no século XIX, os portugueses tomariam conhecimento da região do Vale do Ceará-Mirim a qual agrupava condições naturais favoráveis ao cultivo da cana-de-açúcar, o que despertou o interesse dos lusitanos.

A economia açucareira se estruturou no chamado plantation e tomou como base três elementos básicos: latifúndio, monocultura e trabalho escravo. A plantação da cana desenvolveu, no Brasil, a grande propriedade rural e a sociedade patriarcal e escravocrata. O engenho de açúcar era um empreendimento que exigia um grande volume de recursos para ser iniciado, por isso, as terras eram concedidas àqueles que tinham alguma relação com a coroa portuguesa ou que possuíam recursos para ocupá-las e nelas produzir. Além disso, o cultivo da cana exigia bastante mão-de-obra, o que foi solucionado com a compra de um número cada vez maior de escravos africanos.

De acordo com a PUC-RIO:

Os recursos econômicos e o poder político eram extremamente concentrados. A sociedade da cana-de-açúcar se caracterizava por uma acentuada polarização 
marcada pelo enorme poder e influência local dos senhores de engenho e por um grande número de escravos absolutamente desprovidos de poder econômico, político ou consideração social.

Hoje, sabe-se que a expansão e o desenvolvimento da cultura da cana-de-açúcar na época colonial, aconteceram a partir do uso de práticas agrícolas arcaicas que resultaram no mau uso e contaminação das águas e na consolidação de relações de trabalho que seguiram as tradições e injustiças desse período. Além do mais, as plantações de cana avançaram da fronteira agrícola sobre áreas naturais, principalmente sobre a Mata Atlântica, a qual possui apenas $7 \%$ da sua cobertura original, atualmente (RODRIGUES; ORTIZ, 2006).

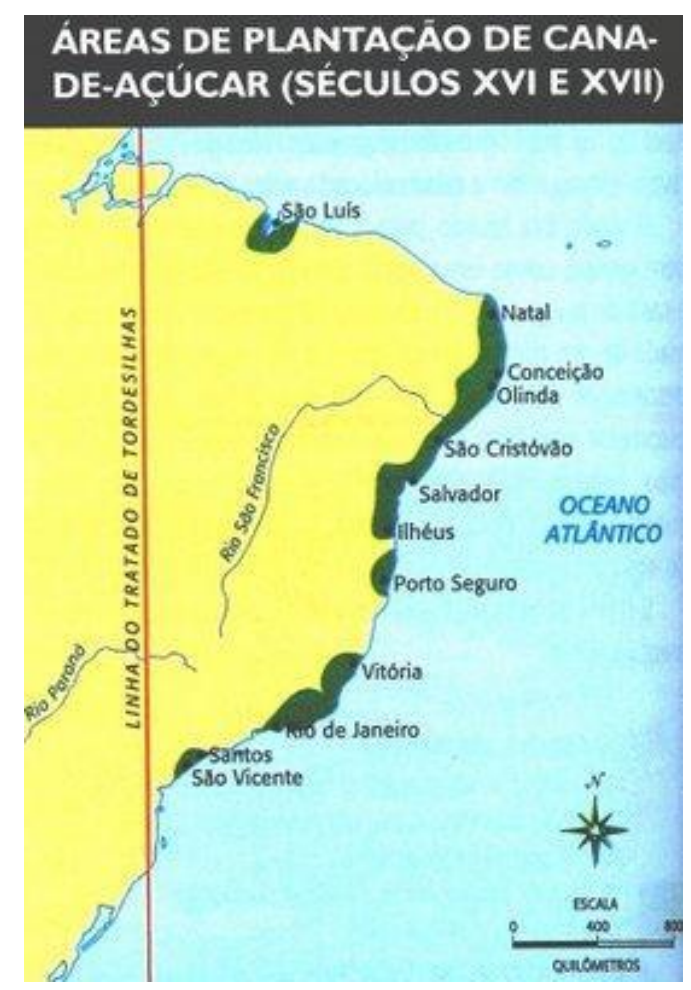

Figura 5 - Área de Plantação de cana-de-açúcar (séculos XVI e XVII).

Disponível em: <http://dialogos6c.blogspot.com/2009/08/cana-de-acucar-passado-e-presente.html>.

\subsection{ASCENSÃO E DECLÍNIO NO VALE DO CEÁRA-MIRIM}

O Vale do Ceará-Mirim apresenta uma história marcada por uma tradicional aristocracia açucareira que dominou a região. Ela começou a ser construída na segunda metade do século XIX, quando foi iniciado o cultivo de cana-de-açúcar ao longo do rio Ceará-Mirim.

Antes disso, a atividade açucareira era inexpressiva e havia poucos engenhos em atividade no espaço norte-rio-grandense. Esses engenhos foram instalados no momento de expansão da economia açucareira pelos colonizadores de capitanias vizinhas, principalmente Pernambuco. Como afirma BERTRAND (2010, p. 31):

[...] foram instalados nas várzeas dos rios da porção oriental os primeiros engenhos: o engenho Cunhaú, moente em 1614, fundado por Jerônimo de Albuquerque, na várzea do rio de mesmo nome e o Ferreiro Torto, fundado em 1630, nas margens do rio Jundiaí. 
Nessa época, a criação de gado era a mais importante atividade econômica da região, principalmente durante a ocupação holandesa. Posteriormente, nos séculos XVIII e XIX, o desenvolvimento do cultivo de algodão contribuiu para uma nova configuração espacial, colocando o Rio Grande do Norte em evidência no cenário agroexportador, porém a seca ocorrida entre os anos de 1844-1846 dizimou o rebanho bovino e, consequentemente, diminuiu os lucros obtidos com a exportação de algodão.

Desta forma, muitos proprietários rurais voltaram seus interesses para a Zona da Mata, área que estava livre dos problemas das longas estiagens, e passaram a investir no cultivo de cana-de-açúcar, uma atividade até então não priorizada na província. "Por apresentar todos os requisitos necessários ao desenvolvimento da cultura açucareira, são instalados, ao longo do rio Ceará-Mirim, em seu médio e baixo curso, engenhos para o cultivo da cana e a produção de açúcar." (BERTRAND, 2010, p. 14) Assim, a região do vale sofreu uma grande transformação, pois anteriormente esse espaço era ocupado pelo cultivo de algodão e pela agricultura de subsistência. Além disso, com o desenvolvimento da economia canavieira, o Vale se tornou a região de maior destaque econômico do estado. Como afirma BERTRAND apud ANDRADE (2010, p. 43 e 44):

Em pouco tempo, o açúcar produzido em Ceará-Mirim irá superar o produzido nas outras regiões açucareiras da província. Em 1860 contavam com 44 engenhos que produziam em média 91 mil arrobas anuais, quando o vale do Papari tinha uma produção média anual de 75 mil arrobas.

Os principais empecilhos para o desenvolvimento desta atividade no Vale eram os causados nas plantações pelas cheias do rio. Assim, várias reclamações foram feitas destacando a necessidade de obras de contenção do rio, porém elas não foram realizadas. Consequentemente, nas primeiras décadas do século XX, houve um desaquecimento da economia açucareira e a região passou a ser ocupada pelo cultivo de policulturas (cacau, milho, mandioca, entre outras).

Outro problema que contribuiu para o declínio da cultura canavieira foram as técnicas utilizadas para o cultivo e a produção de açúcar nos engenhos, que continuavam bem rudimentares. De acordo com BERTRAND, 2010, apud UNIÃO COMERCIAL E AGRÍCOLA, 1913:

\footnotetext{
"A cultura do solo entre nós, infelizmente, ainda obedece a processos rudimentares obsoletos, que se remontam aos tempos primitivos. Com que tristeza, ouvimos nós, não há muito, dizer um especialista estrangeiro que os trabalhos da agricultura nesta terra eram ainda feitas como nos tempos do pai Adão!"
}

Assim, como resultado dessa crise econômica, muitos senhores de engenho abandonaram suas terras, empobrecidos, e a região do Vale do Ceará-Mirim do início do século XIX não lembrava em nada o período de riqueza e prosperidade vivido no auge da cultura canavieira, quando esta era a principal atividade econômica do estado.

Muitas dessas propriedades abandonadas ainda foram incorporadas às usinas que surgiram posteriormente (Ilha Bela, Santa Tereza e São Francisco). No entanto, o Programa PróÁlcool assinalou de fato mais um período de crise para a pequena produção canavieira que havia restado, pois o Vale do Ceará-Mirim não aderiu às suas políticas de reestruturação econômica, tornando-se ainda mais atrasada tecnologicamente em relações às outras regiões. 


\subsection{ETANOL: PIONEIRISMO BRASILEIRO}

“Desde 1925, os brasileiros conheciam a possibilidade da utilização do álcool etílico como combustível" (ANDRADE; CARVALHO; SOUZA, 2009, p. 130). Porém, nesta época, o preço da gasolina não encorajava o desenvolvimento de pesquisas para a produção de um novo combustível para o Brasil.

As primeiras iniciativas comerciais realizadas pelo Brasil e pelos Estados Unidos (os dois maiores produtores mundiais atualmente) ocorreram na década de 1970, motivados pela crise internacional do petróleo, que evidenciou a vulnerabilidade e total dependência energética dos países. Neste novo contexto, o elevado preço da gasolina era um decisivo incentivo à produção do álcool. "Assim, no caso do Brasil o governo passa a financiar e incentivar a produção de etanol de cana-de-açúcar através de subsídios e com a determinação da adição de mistura na gasolina" (LAGO, 2010, p. 02).

A fim de atingir seus objetivos, foi instituído em 14 de novembro de 1975 o Programa Nacional do Álcool, também conhecido como Pró-Álcool, através do Decreto № 76.593, no governo de Ernesto Geisel. Seu início efetivo fundou-se no relatório Etanol como combustível, apresentado pela Secretaria de Tecnologia Industrial (STI) do Ministério da Indústria e Comércio, que possuía como aspecto central o desenvolvimento de tecnologias para a produção de combustíveis a partir da biomassa. Dava-se ênfase às vantagens da exploração da cana-deaçúcar, mas também foi abordado o uso de outras fontes, tais como mandioca.

Na primeira etapa do programa, de 1975 a 1979, as metas se basearam na produção de álcool etílico anidro para ser acrescentado à gasolina. Incentivada pela segunda crise do petróleo, iniciou-se uma nova etapa do Programa: a partir de 1982, o governo investiu no sentido de aumentar as vendas de veículos adaptados ao uso do etanol, ou seja, houve incentivo à produção do álcool combustível (hidratado). Esta ação apresentou grande expressividade e já em 1985, dos carros fabricados no país, 95,8\% eram movidos a álcool (ANDRADE; CARVALHO; SOUZA, 2009, p. 130, apud BARROS, 2007).

Com o desenvolvimento do Programa, na segunda metade dos anos 1970 e nos anos 1980, São Paulo tornou-se a região de plantio com maior importância. De acordo com KOHLHEPP (2010, p. 226):

Desde 1975, registrou-se enorme expansão de áreas cultivadas com cana-deaçúcar e consequente aumento de produção. Isso sobretudo nas regiões principais de plantações em São Paulo - especialmente nos arredores de Ribeirão Preto e Piracicaba com forte expansão até 1987.

A boa infraestrutura apresentada por São Paulo contribuiu para o surgimento de uma densa rede de destilarias, junto às fábricas de açúcar já existentes, principalmente no nordeste e no sudoeste do estado. Além dessas, surgiram também destilarias autônomas ao longo dos eixos das rodovias no oeste de São Paulo, sem ligação às fábricas de açúcar.

As usinas e destilarias aumentaram consideravelmente suas propriedades, havendo uma acirrada concorrência para a ocupação das melhores áreas de plantio, que em poucos estavam esgotadas pela monocultura. Neste contexto, o fornecimento de pequenos e médios produtores diminuiu. 
Apesar do sucesso técnico do programa, havia muitas críticas à sua implementação. Enquanto as áreas para cultivo de alimentos permaneciam as mesmas, aumentavam cada vez mais as áreas de cultivo da cana-de-açúcar. Essa era uma das principais críticas direcionadas ao programa.

Além disso, o caráter sazonal da atividade era visto como um fator negativo, pois os bóiasfrias, mão-de-obra sem vínculo empregatício seguro, só tinham trabalho durante metade do ano, agravando os problemas no campo no período de ociosidade.

Na segunda metade dos anos 1980, o Brasil passava por uma situação econômica desconfortável, em função da inflação, por isso os investimentos do Pró-Álcool foram reduzidos drasticamente. Além disso, em 1986, os preços do petróleo caíram (a US\$13-14/barril), tornando o programa não mais atrativo.

Outros fatores que também contribuíram para o seu declínio foram o aumento do preço do açúcar e a liberalização da exportação do produto em 1988, que acabou reduzindo a produção do etanol e, consequentemente, aumentando seu preço. Em função disso, as vendas dos veículos movidos a gasolina aumentaram, levando, nos anos 1990, ao final da produção de motores movidos somente a etanol.

No final do Programa Pró-Álcool, entretanto, manteve-se a mistura de etanol à gasolina, na proporção de $20 \%$ a $25 \%$, a fim de reduzir as emissões de CO2. "Os investimentos estatais para o programa de produção do etanol para motores de veículos nos setores agrário e industrial foi de US\$ 12,3 bilhões no espaço de tempo de 1975 a 1989" (KOHLHEPP, 2010, p. 228, apud MOREIRA \& GOLDEMBERG, 1999).

Um novo impulso à produção de etanol ocorreu em 2003 com a criação dos carros flex fuel, nos quais podem ser utilizados como combustíveis gasolina, etanol ou os dois. Isso permitiu que o consumidor pudesse optar por qual combustível utilizar, analisando qual está mais rentável naquele momento, ou ainda a opção de utilizar os dois, o que provocou um grande aumento na venda de etanol e, consequentemente, na sua produção. Dessa forma, a partir da adoção dessa medida a produção brasileira de etanol passou a crescer até os dias atuais.

Segundo os últimos dados da União da Indústria de Cana-de-Açúcar (UNICA), o Brasil produziu 27.512.962 milhões de litros de etanol (anidro e hidratado) na safra de 2008/2009, desse total o Rio Grande do Norte contribuiu com 114.909 litros. Nesse mesmo período foram produzidos 569.062.629 toneladas de cana-de-açúcar, das quais 3.186.768 toneladas foram produzidas pelo Rio Grande do Norte. E em 2008, o Brasil exportou 5.118,7 milhões de litros de etanol. Todos esses números aumentam anualmente, provando a capacidade brasileira para a produção desse biocombustível.

O pioneirismo brasileiro na produção mundial de etanol pode ser facilmente visualizado na figura 5, na qual se tem a comparação da produção brasileira, com a norte-americana e canadense, e européia, fazendo um paralelo com a produção mundial. 


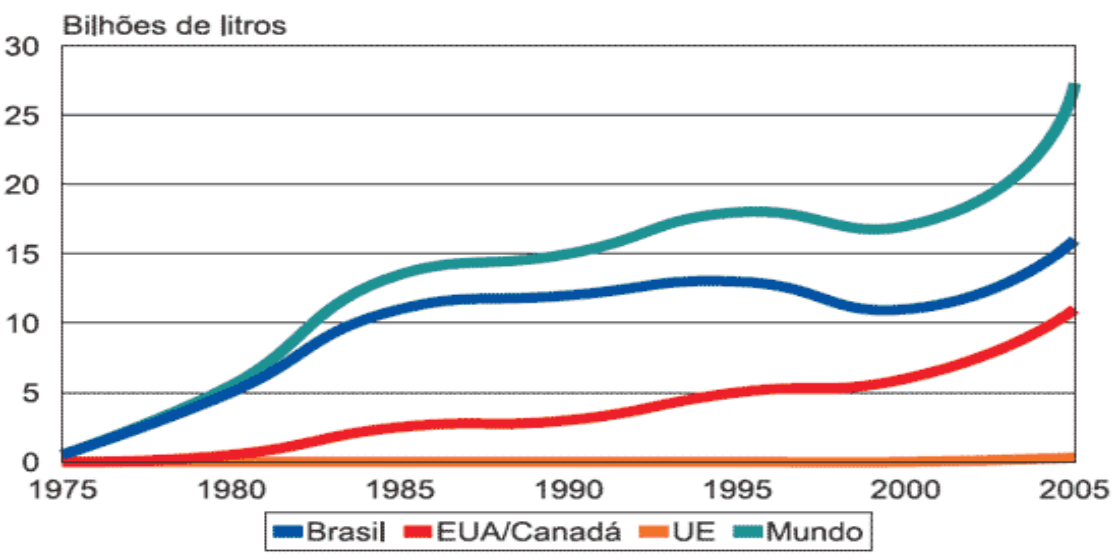

Figura 6 - Produção de etanol no Brasil e no mundo. Fonte: Álcool - etanol brasileiro.

Disponível em: < http://www.biodieselbr.com/energia/alcool/etanol.htm>.

O grande potencial para a produção de cana-de-açúcar como, por exemplo, grande quantidade de terras disponíveis e com solos propícios para esse cultivo, é um dos principais fatores que contribui para que o Brasil seja líder mundial na produção de etanol. Além do mais o grande potencial energético advindo dessa biomassa, como podemos constatar a partir da tabela 3 , faz com que o etanol brasileiro se destaque.

Tabela 3: Balanço energético proveniente de algumas matérias-primas do etanol

\begin{tabular}{l|c}
\hline Matérias-primas & Energia renovável / energia fóssil usada \\
\hline Etanol de milho (USA) & 1,3 \\
\hline Etanol de cana (Brasil) & 8,9 \\
\hline Etanol de beterraba (Alemanha) & 2,0 \\
\hline Etanol de sorgo sacarino (África) & 4,0 \\
\hline Etanol de trigo (Europa) & 2,0 \\
\hline Etanol de mandioca & 1,0 \\
\hline
\end{tabular}

Fonte: MACEDO, I. C. Situação atual e perspectivas do etanol. Disponível em: <http://www.scielo.br/pdf/ea/v21n59/a11v2159.pdf>. Acesso em: 08 fev. 2011.

Atualmente a cana-de-açúcar ocupa, aproximadamente, $9 \%$ das áreas cultiváveis brasileiras. Ela vem sendo cultivada em quase todos os estados brasileiros, com destaque para São Paulo, estado que é responsável pela maior parte da produção de cana-de-açúcar e etanol do Brasil, isso por causa das suas condições de solo e de clima favoráveis, boa infra-estrutura de transportes, proximidade dos mercadores consumidores e utilização de pesquisas e tecnologias para incrementar cada vez mais a produção de tais produtos.

Segundo BNDES, et. al (2008, p. 156) o Brasil possui mais de 330 usinas espalhadas pelo seu território. E elas podem ser classificadas em três grupos: usinas que produzem apenas açúcar; usinas que apresentam destilarias, ou seja, produzem açúcar e etanol; e destilarias que produzem apenas etanol. Dentre esses, o grupo que mais se destaca é o que produz açúcar e etanol, sendo composto por $60 \%$ das usinas brasileiras.

Tendo em vista a situação financeira, as usinas brasileiras também se classificam em três outros grupos: estagnadas (usinas que estão em um estado crítico, devido ao acúmulo de dívidas e por possuírem tecnologias ultrapassadas, que fazem com que essas usinas percam a possibilidade de competir no mercado); lucrativas (aquelas que foram capazes de se adaptar às 
inovações tecnológicas que foram surgindo, garantindo seu espaço no mercado internacional); e inovadoras (aquelas que independentemente, ou com parcerias com multinacionais, estão sempre diversificando suas tecnologias e procurando valorizar cada vez mais a cana-de-açúcar, aumentando assim a reutilização dos subprodutos e co-produtos da cana como também os lucros da empresa).

Atualmente, o setor da agroindústria do açúcar e do etanol no Brasil conta com investimentos de capitais de companhias privadas nacionais e internacionais, faltando ainda mais investimentos e programas de incentivos por parte do governo, fazendo com que esse biocombustível torne-se cada vez mais viável.

\section{CONSIDERAÇÕES FINAIS}

O Brasil apresenta um alto potencial para o desenvolvimento de matrizes energéticas "limpas". Em se tratando da região de Ceará-Mirim esse potencial, ainda pouco aproveitado, está relacionado com a produção de etanol a partir da cana-de-açúcar. A partir do momento em que estudos sobre tal temática na redondeza do município citado vão sendo realizados, é possível enfatizar a capacidade da região para a produção de tal combustível, fazendo com que novos interesses surjam e promovam o desenvolvimento daquele local, provocando também uma mudança na matriz energética, o que trará muitos benefícios, principalmente no aspecto ambiental. Além disso tal estudo foi responsável por ampliar os nossos conhecimentos sobre a temática, tornando-se ainda mais importante por se tratar de uma área próxima à realidade social e de formação educacional do grupo.

Diante da possibilidade de escassez de combustíveis, dos problemas ambientais agravados a cada dia - advindos da utilização de fontes energéticas poluentes, e do reconhecimento da relevância da energia para a realização de todas as atividades que condicionam a vida humana, pensar na utilização de energias renováveis é a atitude mais natural e adequada para a resolução de tal problemática.

Por meio de estudos, pesquisas e constatações já foi provada a eficiência da utilização do etanol como combustível, e as vantagens da sua utilização superam às de outros combustíveis muito utilizados atualmente - como a gasolina. Dessa forma, para que uma substituição, ou ao menos uma complementação mais participativa, da matriz energética ocorra, ainda é preciso realizar mais investimentos na produção do etanol, aproveitando todo o potencial que o Brasil possui para esse biocombustível - especialmente o da região de Ceará-Mirim, que sofre até hoje as consequências da exclusão tecnológica - e desenvolvendo métodos de aproveitamento para todos os subprodutos do processo produtivo do etanol, o que aumentará ainda mais a rentabilidade e a viabilidade do produto final.

\section{REFERÊNCIAS}

1. AGÊNCIA NACIONAL DE ENERGIA ELÉTRICA. Biomassa. Disponível em: <http://www.aneel.gov.br/aplicacoes/atlas/pdf/05-Biomassa\%282\%29.pdf>. Acesso em: 14 mai. 2011.

2. AMBIENTE BRASIL. Biomassa - 0 que?. Disponível em: <http://ambientes.ambientebrasil. com.br/energia/biomassa/biomassa_-_o_que_\%3F.html>. Acesso em: 14 mai. 2011. 
3. ANDRADE, E. T. de; CARVAlHO, S. R. G. de; SOUZA, L. F. de. Programa do Proálcool e o etanol no Brasil. Disponível em: <http://www.uff.br/engevista/seer/index.php/engevista/ article/viewArticle/236>. Acesso em: 19 mar. 2011.

4. BERTRAND, Daniel. Patrimônio, memória e espaço: a construção da paisagem açucareira do Vale do Ceará-Mirim. Natal: UFRN. 2010.

5. BIODIESELBR. Álcool - etanol brasileiro. Disponível em: <http://www.biodieselbr.com/ energia/alcool/etanol.htm>. Acesso em: 16 fev. 2011.

6. BNDES. et al. Bioetanol de cana-de-açúcar: energia para o desenvolvimento sustentável. Disponível em: <http://www.bioetanoldecana.org/pt/download/resumo_executivo.pdf>. Acesso em: 10 dez. 2010.

7. BNDES. et al. Sugarcane-Based Bioethanol: Energy for Sustainable Development. 1st ed. Rio de Janeiro: BNDES' Communication Department, 2008.

8. CONSVITA. Matrizes energéticas: Petróleo e Biocombustíveis. Disponível em: <http://boletiminternacional.wordpress.com/2009/02/28/matrizes-energeticas-petroleo-ebiocombustivel/>. Acesso em: 08 fev. 2011.

9. DEPARTAMENTO DA CANA-DE-AÇÚCAR E AGROENERGIA. Açúcar e álcool no Brasil. Disponível em: <http://www.agencia.cnptia.embrapa.br/Repositorio/alcool_acucar_no_brasil_mapa_ 000fl6j9ex702wyiv80ispcrrqur3jqt.pdf>. Acesso em: 19 jan. 2011.

10. FONSECA, V. M. da; BRAGA, S. R. Para além da geopolítica do etanol: novos discursos e velhas práticas do setor canavieiro no Brasil. Disponível em: <http://www4.fct.unesp. br/ceget/PEGADA91/05-9-1-WalterSandra.pdf>. Acesso em: 20 jan. 2011.

11. GOLDEMBERG, J.; LUCON, O. Energia e meio ambiente no Brasil. Disponível em: <http://www.scielo.br/pdf/ea/v21n59/a02v2159.pdf>. Acesso em: 29 ago. 2011.

12. KOHLHEPP, G. Análise da situação da produção de etanol e biodiesel no Brasil. Disponível em: <http://www.scielo.br/pdf/ea/v24n68/17.pdf>. Acesso em: 08 fev. 2011.

13. LAGO, A. Etanol de celulose versus etanol de cana-de-açúcar. Disponível em: <http://www.alasru.org/cdalasru2010/1\%20trabalhos\%20completos/gt-12/26-8/GT12\%20 Adriano\%20Lago.pdf>. Acesso em: 20 jan. 2011.

14. MACEDO, I. C. Situação atual e perspectivas do etanol. Disponível em: <http://www.scielo.br/pdf/ea/v21n59/a11v2159.pdf>. Acesso em: 08 fev. 2011.

15. MONTENEGRO, M. E. A produção do espaço rural no município de Ceará-Mirim. Natal, 2004.

16. MOREIRA, G. R. Z. Promover Desenvolvimento e Sustentabilidade Através de Energias Renováveis. Disponível em: <http://www.adjutojunior.com.br/tcc/Promover_Desenvolvi mento_e_Sustentabilidade_Atraves_de_Energias_Renovaveis_Giuliano_Robledo_Zucoloto_ Moreira.pdf>. Acesso em: 15 mai. 2011.

17. NETO, M. Processo de produção de bioetanol. Disponível em: <http://brasilbio. blogspot.com/2007/11/processo-de-produo-de-bioetanol.html>. Acesso em: 01 ago. 2011.

18. OTTONI, M. A. M. Etanol da cana-de-açúcar: consequências sociais e ambientais. Disponível em: <http://www.uniesp.edu.br/revista/revista9/pdf/artigos/14.pdf>. Acesso em: 20 out. 
2010.

19. PUC-RIO. Os Ciclos da Cana-de-Açúcar e do Ouro na História Colonial Brasileira. Disponível em: <http://www2.dbd.puc-rio.br/pergamum/tesesabertas/0510685_07_cap_04.pdf>. Acesso em: 03 ago. 2011.

20. RODRIGUES, D.; ORTIZ, L. Em direção à sustentabilidade da produção de etanol de cana-deaçúcar no Brasil. Disponível em: <http://www.vitaecivilis.org.br/anexos/etanol_ sustentabilidade.pdf>. Acesso em 03 maio. 2011.

21. SECRETARIA DE POLÍTICA AGRÍCOLA DO MINISTÉRIO DA AGRICULTURA, PECUÁRIA E ABASTECIMENTO. Etanol, meio ambiente e tecnologia. Revista de política agrícola, Brasília, n. 3, p. 53-62, 2006. Disponível em: <http://www.embrapa.br/publicacoes/tecnico/ revistaAgricola/rpa-de-2006/pol_agr_03-2006.pdf\#page=52>. Acesso em: 30 jul. 2011.

22. SILVA, E. M. de P. e; SAKATSUME, F. A política brasileira de biocombustíveis. Disponível em:<http://www.conservation.org.br/publicacoes/files/7_Politica_Biocombust_E_Mirra.pdf $>$. Acesso em: 14 mar. 2011.

23. UNIÃO DA INDÚSTRIA DE CANA-DE-AÇÚCAR. Etanol e Bioeletricidade: A cana-de-açúcar no futuro da matriz energética. Disponível em: <http://www.unica.com.br/Downloads/ estudosmatrizenergetica/pdf/livro-etanol-bioeletricidade.pdf>. Acesso em: 08 fev. 2011.

24. UNIÃO DA INDÚSTRIA DE CANA-DE-AÇÚCAR. Produção e uso do etanol combustível no Brasil. Disponível em: <http://www.ie.ufrj.br/infosucro/biblioteca/bic_Unica_ProducaoUsoEtanol .pdf>. Acesso em: 09 nov. 2010.

25. USINA ESTER. O processo de fabricação de açúcar e álcool na usina Ester. Disponível em: < http://www.usinaester.com.br/Produtos/produtos.html>. Acesso em: 02 ago. 2011. 